\title{
Ionic Polymerization of $p$-Methoxystyrene and Other Styrene Derivatives by Radiation
}

\author{
Kanae Hayashi* and David C. Pepper \\ Chemical Laboratory, Trinity College, Dublin, Ireland. \\ (Received October 30, 1974)
}

\begin{abstract}
Polymerization of $p$-methoxystyrene by radiation was studied in bulk. Upon drying the monomer, the rate of polymerization, $R_{\mathrm{p}}$, became greater, changing its dose rate dependence from 0.5 to 1 . The molecular weight distribution of the ottained polymers failed to give a bimodal curve; however, the peak molecular weight increased with higher $R_{\mathrm{p}}$. These kinetic features can be explained by a coexistence of radical and cationic mechanisms, as has been established in styrene, though there remain ambiguities about the effects of additives. Copolymerizations with styrene and 2-chloroethyl vinyl ether also showed a cationic nature for the reaction. A survey of possibilities of ionic polymerization by radiation was also carried out in ten ring-substituted styrene derivatives.
\end{abstract}

KEY WORDS Cationic Polymerization / Radiation / $p$-Methoxystyrene / Molecular Weight Distribution / Copolymerization / RingSubstituted Styrenes /

It has been well established that the polymerization initiated by ionizing radiation goes by free-ionic species, that is, free from the influence of its counterpart of opposite sign. ${ }^{1,2}$ In a word, it is a polymerization by a highly reactive intermediate of relatively short lifetime at very low concentration, in contrast to the conventional polymerization by catalyst. For instance, in the cationic polymerization of styrene, ${ }^{3}$ the free ion makes a chain propagation at a rate of ten monomer additions every microsecond during its lifetime of $c a$. $100 \mathrm{msec}$ at a steady state concentration of $10^{-9} \mathrm{M}$.

Up to this time, kinetic studies of the cationic polymerization by radiation have been concentrated on a small number of vinyl compounds, such as styrene,,$^{2-7} \alpha$-methylstyrene, ${ }^{1,2,8}$ vinyl ethers, ${ }^{2,9,10}$ isobutene, ${ }^{11,12}$ and other monomers have remained almost untouched. p-Methoxystyrene ( $p$-MeOSt) was chosen for two reasons. First, a greater reactivity for $p$-MeOSt compared with styrene is expected in a radiation-induced reaction, from the Hammet rule for cationic propagation of styrene derivatives by catalyst initiation. ${ }^{13}$ Another point of interest is the

\footnotetext{
* Present Address: Osaka Laboratory for Radiation Chemistry, Japan Atomic Energy Research Institute. 25-1, Mii-minami-cho, Neyagawa, Osaka.
}

influence of the methoxy group upon the propagation reaction. In studies of isobutyl vinyl ether, ${ }^{9,14}$ a combined effect of solvation of the propagating cation-end by orienting the oxygen atom of the monomer to the cation and of resonance stabilization of the cation-end has been proposed. In anionic polymerization of $o$-methoxystyrene, ${ }^{15}$ a marked solvation effect of the polymeric anion-alkali metal cation pair by the methoxy oxygen atom has been pointed out. However, in $p$-MeOSt, coordination with monomer oxygen may be less likely to favor the propagation, since the reacting vinyl group is further away from it.

Polymerization of $p$-MeOSt by radiation was first studied in a copolymerization system with styrene, ${ }^{16}$ but failed to show any cationic reaction. Later, Chen ${ }^{17}$ claimed that there was a cationic mechanism in methylene chloride at low temperature. However nothing is clear yet about the details of the polymerization.

In addition, the possibility of ionic polymerization was also studied in ten ring-substituted styrenes.

\section{EXPERIMENTAL}

All the styrene derivatives including $p$-MeOSt 


\section{K. Hayashi and D. C. Pepper}

were supplied by Koch-Light Lab. Ltd. In $p$ MeOSt studies, the monomer was dried with calcium hydride and distilled under reduced pressure. Then the monomer was degassed in a vacuum system and dried by repeated contacts with silica gel (W. R. Grace Ltd.) which had been baked at $400-450^{\circ} \mathrm{C}$ for two days. All the ampoules and tubes connected to the vacuum system were heated in an electric oven or baked out with flame to achieve $10^{-6}$-torr vacuum. Finally, the monomer was vacuum-distilled into a reservoir ampoule situated at the neck of the dilatometer and sealed off. After the monomer level had been carefully adjusted for measurement, the dilatometer was separated from the reservoir assembly by flame sealing.

Copolymerization samples were prepared by distilling dry monomer into graduated ampoules with break seal tubes; these were sealed off one by one. These ampoules were connected to the vacuum system again through their break seal tubes. Then the second monomer was introduced into each ampoule after crushing the break seal tip and sealed off one by one. Oxygen or ammonia gas was introduced into the monomer ampoule from a tube containing activated molecular sieves 4A.

Irradiations were made by ${ }^{60} \mathrm{Co} \gamma$-rays. The chemical dosimetry was carried out using a Fricke solution. The polymer conversion was kept less than $5 \%$ generally and less than $2 \%$ in the copolymerization studies. The polymers or copolymers obtained were precipitated into a large excess of methanol, filtered, and dried in a vacuum oven at $c a \cdot 60^{\circ} \mathrm{C}$. In the case of copolymer with 2-CEVE, the reaction mixture was vacuum-dried without precipitation.

Gel permeation chromatograph (GPC) measurements were made in $o$-dichlorobenzene solution at room temperature using three polystyrene gel columns of limiting pore size $10^{4}, 10^{5}$, and $10^{6} \mathrm{~A}$, respectively.

The $p$-MeOSt-styrene copolymer composition was determined by IR analysis using 700 and $826 \mathrm{~cm}^{-1}$ absorptions for styrene and $p$-MeOSt, respectively. The fraction of $p$-MeOSt unit in copolymer, $F_{\mathrm{MeOS}}$, is given by

$$
F_{\mathrm{MeOSt}}=\frac{O D_{\mathrm{MeOSt}}}{O D_{\mathrm{MeOSt}}+f \cdot O D_{\mathrm{St}}}
$$

The relative sensitivity factor, $f$ was determined to be 0.67 from the elementary analysis of the copolymers. For $p$-MeOSt-2-CEVE copolymer analysis, chlorine content by elementary analysis was employed.

\section{RESULTS AND DISCUSSION}

\section{The Dose Rate Dependence with p-MeOSt}

The polymerization rate, $R_{\mathrm{p}}$ as a function of dose rate is shown in Figure 1. Irreproducibility of the results is really a chronic disease of this kind of work ${ }^{4,5,7,11}$ and it often happens that considerable differences in $R_{\mathrm{p}}$ arise between samples which were dried using procedures which were as far as possible identical. The dose rate exponent of $R_{\mathrm{p}}$ changed from 0.5 in samples $\mathrm{I}$ and $\mathrm{F}$, [curves (f) and (g)] to $0.8-0.9$ in samples $\mathrm{O}, \mathrm{D}$, and $\mathrm{E}$ [curves (a), (b), and (c)] with increase of the $R_{\mathrm{p}}$. The dose rate exponent of $R_{\mathrm{p}}$ in sample $\mathrm{O}$, which showed the highest rate in our experiment, was still 0.8 .

This kinetic behavior agrees with the consequence of the previously proposed kinetics for styrene, ${ }^{18}$ where a coexistence of radical and cationic mechanisms was taken into account. This is, only the radical polymerization denoted by the half power dose rate dependence of $R_{\mathrm{p}}$ takes place in wet monomer. Upon drying the monomer, the cationic process is added to the

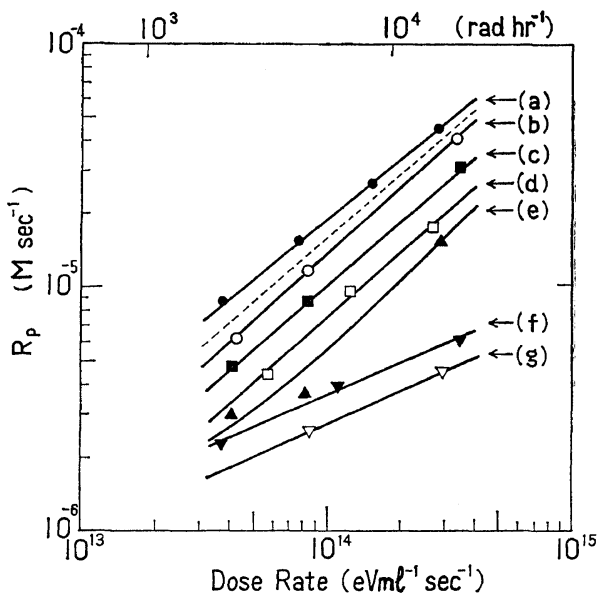

Figure 1. Polymerization of $p$-MeOSt in bulk at $25^{\circ} \mathrm{C}$ : (a), sample $\mathrm{O}$; (b), sample $\mathrm{D}$; (c), sample E; (d), sample Q; (e), sample K; (f), sample I; (g), sample $\mathrm{F}$; dotted line, see the text. 
radical one, yielding a rise of $R_{\mathrm{p}}$ with the increase of the dose-rate dependence toward one. Further drying will enhance the cationic $R_{\mathrm{p}}$, while the dose-rate dependence approaches 0.5 again. If these kinetics can be applied to the present case, our results indicate there is still a poor degree of dryness. When the contribution of the radical mechanism, presumably equal to $R_{\mathrm{p}}$ in sample I, was subtracted from the $R_{\mathrm{p}}$ in sample $O$, the difference, shown with a dotted line in Figure 1, was approximately proportional to the 0.9 power of the dose rate. This means that most of the propagating chains are terminated by a degradative chain transfer to an impurity molecule, i.e., water. Attempts to get higher $R_{\mathrm{p}}$ values to approach the ultimate halfpower dependence were unsuccessful because of the difficulty in drying the monomer.

In sample $\mathrm{F}$, the $R_{\mathrm{p}}$ level is considerably lower than that in sample $I$, though the radical mechanism is supposed to be predominant in both systems. This is probably due to an accidental contamination by some retarding species in sample F. Assuming the result in sample I as the highest $R_{\mathrm{p}}$ attainable in our reaction conditions with the radical mechanism, $R_{\mathrm{p}}$ in the radical mechanism is $c a .50 \%$ greater than that for styrene ${ }^{19}$ at the

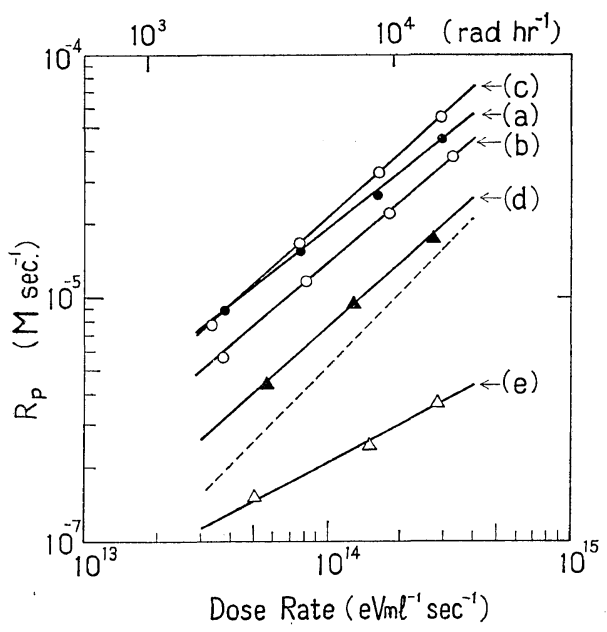

Figure 2. Polymerization of $p$-MeOSt in bulk: (a), sample $\mathrm{O}$, in vacuo, $25^{\circ} \mathrm{C}$; (b), sample $\mathrm{O}$, in vacuo, $0^{\circ} \mathrm{C}$; (c), sample $\mathrm{O}, 100$-torr $\mathrm{O}_{2}, 25^{\circ} \mathrm{C}$; (d), sample $\mathrm{Q}$, in vacuo, $25^{\circ} \mathrm{C}$; (e), sample $\mathrm{Q}$, 110-torr $\mathrm{NH}_{3}, 25^{\circ} \mathrm{C}$; dotted line, see the text. (a) and (d) are the same runs as (a) and (d) in Figure 1, respectively. same dose rate. This may be mainly attributed to a greater $k_{\mathrm{p}} / k_{\mathrm{t}}{ }^{1 / 2}$ ratio in $p$-MeOSt. ${ }^{20}$

The lowering of the polymerization temperature to $0^{\circ} \mathrm{C}$ in sample $\mathrm{O}$ gave a $20-30-\%$ decrease in $R_{\mathrm{p}}$, giving the slightly steeper slope shown with curve (b) in Figure 2. This gives an apparent activation energy of overall $R_{\mathrm{p}}$ of $c a .2 \mathrm{kcal} / \mathrm{mol}$, which coincides with the value in styrene. ${ }^{3}$ This suggests that the contribution of solvation and resonance stabilization of the propagating end is much less in $p$-MeOSt than that of vinyl ether. ${ }^{14}$

An introduction of $c a$. 100-torr oxygen to the same sample gave small increases in $R_{\mathrm{p}}$ in the high dose-rate region and also in the doserate exponent, as shown with curve (c) in Figure 2. This is the opposite trend to the case in styrene, ${ }^{3}$ where $R_{\mathrm{p}}$ decreased despite the decrease of the dose-rate exponent by oxygen addition.

Addition of ammonia, ca. 110 torr, to sample Q greatly suppressed $R_{\mathrm{p}}$. Subtraction of curve (e) from curve (d), i.e., the fraction of $R_{\mathrm{p}}$ inhibited by ammonia, gave a straight line of 1.0 dose-rate dependence, as shown with a dotted line in Figure 2. This means that ammonia killed the entire cationic reaction, leaving only the contribution of the radical mechanism, which is somehow considerably lower than that in sample I.

GPC curves of poly ( $p$-MeOSt $)$ are shown in Figure 3. For each polymer, $R_{\mathrm{p}}$ at some fixed dose rate is given in the description of Figure 3. The relatively poor resolution in our columns, and the lack of a molecular weight (MW)elution count relationship in the very high MW region did not allow us to obtain average $\mathrm{MW}$ calculations. The samples of curves (a) and (b) were polymerized in ampoules. From the $R_{\mathrm{p}}$ value, the former is considered to be mostly due to the radical mechanism, even taking account of the lower reaction temperature. The samples of curves (c) and (d) are the polymers recovered after the dilatometry shown with curves (e) and (b) in Figure 1, respectively.

The influences of oxygen and ammonia on MW distribution were also studied using the same batches of monomer as samples $O$ and $Q$ in Figures 1 and 2. As shown in curve (e), an increase of MW was found with a small increase 


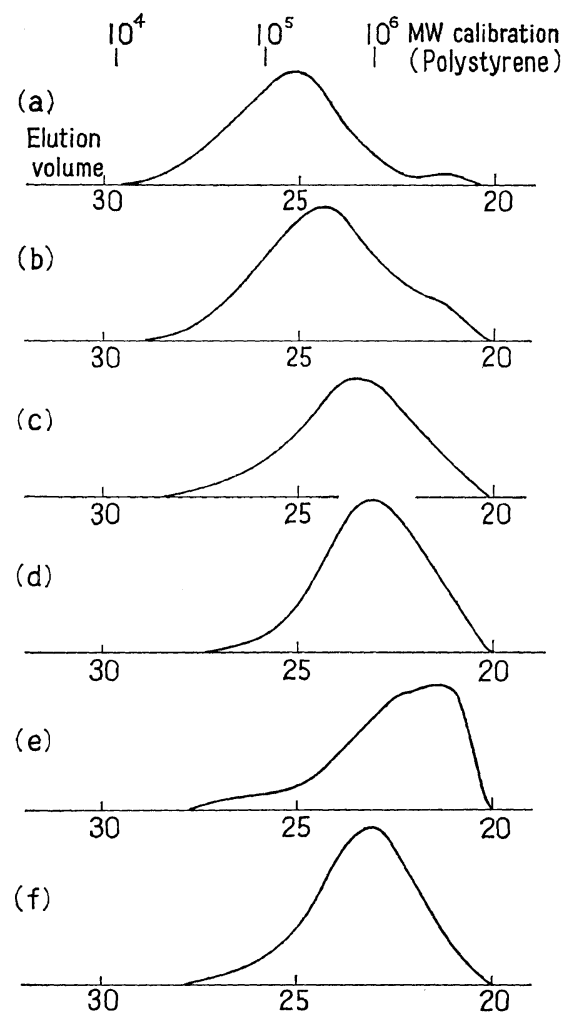

Figure 3. GPC curves of poly( $p$-MeOSt) obtained in various systems.

Sample Additive $\begin{aligned} & \text { Polym } \\ & \text { temp, Dose rate, }\end{aligned} 10^{5} R_{\mathrm{p}}$, ${ }_{0}^{\circ} \mathrm{C}, \mathrm{eV} / \mathrm{m} l \mathrm{sec} \quad \mathrm{mol} / l \mathrm{sec}$

$\begin{array}{lllccc}\text { (a) } & \mathrm{X} 11 & \text { vacuum } & 12-15 & 3.8 & 0.4 \\ \text { (b) } & \mathrm{V} 9 & \text { vacuum } & 25 & 3.6 & 1.0 \\ \text { (c) } & \mathrm{K} & \text { vacuum } & 25 & 3.0 & 1.5 \\ \text { (d) } & \mathrm{D} & \text { vacuum } & 25 & 3.4 & 4.0 \\ \text { (e) } & \mathrm{O}^{\prime} & 100 \text {-torr } \mathrm{O}_{2} & 25 & 2.8 & 5.4 \\ \text { (f) } & \mathrm{Q}^{\prime} & 110 \text {-torr } \mathrm{NH}_{3} 25 & 2.8 & 0.8\end{array}$

of $R_{p}$ by the addition of oxygen, an inhibitor of radical propagation. The addition of ammonia, an inhibitor of cationic propagation did not reduce the $\mathrm{MW}$ in spite of the $R_{\mathrm{p}}$ decrease, as shown in curve (f) of Figure 3.

From curves (a)-(d) in Figure 3, we notice a gradual shift of the peak to higher MW with higher $R_{\mathrm{p}}$ regardless of the reaction mechanism. The small shoulder at the extremely high MW region of curves (a) and (b) is not considered to be related with the main process of cationic mechanism, since in other samples of greater $R_{\mathrm{p}}$ 's it does not become greater but is incorpo- rated with the tail of the main peak. If radical and cationic polymerizations are taking place at the same time, a bimodal distribution is expected $^{7,21}$ when the reaction conditions, mainly dose rate and temperature, are suitably chosen. In our case, it is likely that two different distribution curves of not too distant peaks are merged to give a single-peaked composite distribution, if we may disregard the small, extremely high MW peaks. This explains the peak shift to higher MW with the increase of $R_{\mathrm{p}}$.

However, the influences of oxygen and ammonia additions on MW are not well explained with our present understanding of the radicalcation coexistence hypothesis. It is rather strange that the effects of the additives in $p$-MeOSt are not similar to those in styrene and further studies are required for a comprehensive elucidation of the polymerization mechanism in these monomers.

\section{Copolymerizations with Styrene and 2-CEVE}

Copolymerizations of $p$-MeOSt with styrene and 2-CEVE were carried out also in bulk to confirm the cationic nature of the polymerization. In the $p$-MeOSt-styrene system, copolymer yields were generally low, in most cases approximately four times greater than the calculated polymer yields attributable to the radical mechanism. These low rates of copolymerization can be attributed to less sufficient drying of the samples and perhaps to a greater sensitivity of $p$-MeOSt cation to water. The GPC curves of the copolymers were broad and vague, suggesting that we cannot exclude a minor contribution of the radical mechanism. In the $p$-MeOSt-2-CEVE system, the contribution of the radical mechanism was estimated to be much smaller.

Copolymerization with styrene was carried out at 0 and $40^{\circ} \mathrm{C}$. As shown in Figure 4, scatter in our results prevented a derivation of the temperature dependence of the reactivity ratios, though it seems small. The values obtained are

$$
r_{1}=2.9 \text { and } r_{2}=0.055
$$

where $M_{1}$ is $p$-MeOSt.

The following results are already known from previous research using catalysts:

Radical mechanism 


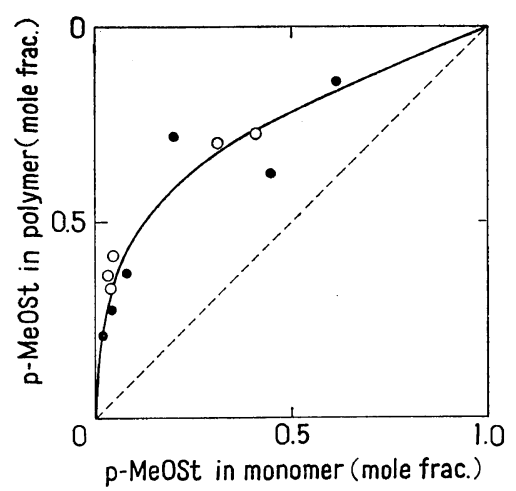

Figure 4. Copolymerization of $p$-MeOSt with styrene in bulk: $\bigcirc, 0^{\circ} \mathrm{C}$; $25^{\circ} \mathrm{C}$.

(BPO, bulk; $\left.60^{\circ} \mathrm{C}\right),{ }^{22} r_{1}=0.82, r_{2}=1.16$

Cationic mechanism

$$
\begin{aligned}
& \left(\mathrm{BF}_{3} \mathrm{OEt}_{2}, \mathrm{CHCl}_{3} ; 30^{\circ} \mathrm{C}\right),{ }^{23} r_{1}=38, r_{2}=0.5 \\
& \left(\mathrm{SnCl}_{14}, 1: 1-\mathrm{PhNO}_{2}-\mathrm{CCl}_{4} ; 0^{\circ} \mathrm{C}\right),{ }^{24} \\
& r_{1}=19-29, r_{2}=0 \\
& \left(\mathrm{TiCl}_{4}, 1: 1-\mathrm{PhNO}_{2}-\mathrm{CCl}_{4} ; 0^{\circ} \mathrm{C}\right),{ }^{24} \\
& r_{1}=11.5-14, r_{2}=0.12-0.38 \\
& \left(\mathrm{AlCl}_{3}, 1: 1-\mathrm{PhNO}_{2}-\mathrm{CCl}_{4} ; 0^{\circ} \mathrm{C}\right),{ }^{24} \\
& r_{1}=11, r_{2}=0.34
\end{aligned}
$$

Anionic mechanism

$$
\left(\mathrm{Na}^{+}, \mathrm{THF} ; 25^{\circ} \mathrm{C}\right),{ }^{25} r_{1}=0.045, r_{2}=19
$$

Burlant ${ }^{16}$ obtained $r_{1}=1.5$ and $r_{2}=0.70$ at $60^{\circ} \mathrm{C}$ in bulk by radiation, indicating a radical mechanism. On the basis of the greater reactivity of $p$-MeOSt compared with styrene in the cationic mechanism, the most probable mechanism in our system must be cationic. Our very low $r_{2}$ value in comparison with $r_{2}$ in the radical polymerization, seems to indicate a smaller contribution of the radical mechanism than was our expection in the earlier part. From the reactivity ratios above, we notice a trend, that with the strength of catalyst, $r_{1}$ becomes smaller, while the variation of $r_{2}$ is a little scattered, and that our values by radiation initiation lie on the extrapolation of this trend to much stronger catalyst.

Because of the difficulties of removing involatile, unreacted $p$-MeOSt from the reaction mixture and of chlorine elimination by heat in the vacuum oven, the copolymerization results with 2-CEVE are very scattered, as shown in Figure 5. The approximate value of reactivity ratios are

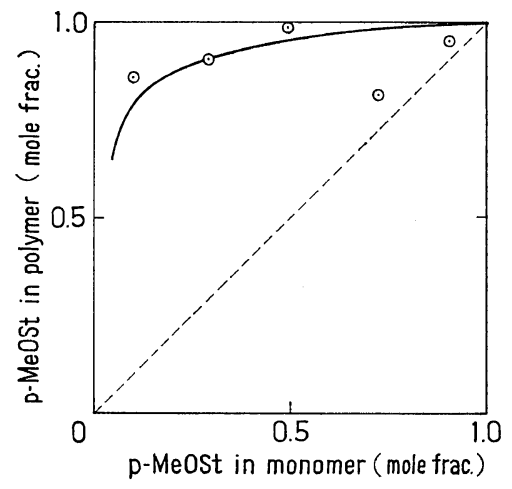

Figure 5. Copolymerization of $p$-MeOSt with 2CEVE at $0^{\circ} \mathrm{C}$ in bulk.

$$
r_{1}=30 \text { and } r_{2}=0
$$

where $M_{1}$ is $p$-MeOSt.

In this system, following results have been reported: $:^{26}$

$\mathrm{BF}_{3} \mathrm{OEt}_{2}$, toluene; $0^{\circ} \mathrm{C}, r_{1}=1.55, r_{2}=9.32$

$\mathrm{BF}_{3} \mathrm{OEt}_{2}, \mathrm{CH}_{2} \mathrm{Cl}_{2} ; 0^{\circ} \mathrm{C}, r_{1}=9.25, r_{2}=1.63$

$\mathrm{SnCl}_{4}-\mathrm{CCl}_{3} \mathrm{COOH}, \mathrm{CH}_{2} \mathrm{Cl}_{2} ; 0^{\circ} \mathrm{C}$,

$$
r_{1}=12.1, r_{2}=1.24
$$

From those values we can see that with stronger catalyst and/or polar solvent, $r_{1}$ becomes greater, while $r_{2}$ falls down; again our result by radiation falls on the extrapolation of this trend to much stronger catalyst. This finding was first pointed out by one of us in the copolymerization of styrene with isobutyl vinyl ether. ${ }^{14}$

In analogy with living anion polymerization, it has been posturated in the cationic polymerization by catalyst that generally three different states of the propagating chain are coexisting in equilibria: polarized molecules, ion pairs, and free ions. ${ }^{27}$ This was partly confirmed by bimodal MW distributions obtained in several systems, ${ }^{27,28}$ though it is not clear which is which at the moment. On the other hand, free-ionic polymerization has been found in some systems initiated by stable salts ${ }^{29,30}$ and strong acid. ${ }^{27}$ Therefore a mixture of two or three copolymers of different compositions is expected in copolymerization, since it is quite natural to consider that the reactivity ratios greatly depend on the nature of the chain end. This may account for the abovementioned trend by arguing that the fraction of 
copolymer formed by free ions increases with stronger catalyst, and postulating a free-ionic mechanism in the polymerization by radiation.

\section{Comparison of Different Substituted Styrenes}

The possibility of ionic polymerization by radiation was also studied in ten ring-substituted styrenes in bulk. Two samples were prepared for each monomer: one was dried by the same procedures as were used in $p$-MeOSt (dry run), and the other was dried only by calcium hydride (wet run). Styrene samples were also prepared to make a check of the drying techniques in the two runs.

The following criteria were used to distinguish ionic from radical polymerization: $1 . R_{\mathrm{p}}$ increase by drying and $R_{\mathrm{p}}$ ratio relative to that in styrene in radical mechanism. 2. The GPC curves.

It is well known that the elimination of water from a monomer greatly enchances the reaction rate in ionic polymerization by radiation. , $^{4,8,11}$ However, as water is an inhibitor for a free-anionic reaction as well as for a free-cationic one, an increase of $R_{\mathrm{p}}$ by drying itself does not tell us whether the probable mechanism is anionic or cationic. The MW distribution obtained by GPC also gives indication as to the reaction mechanism in polymerization studies which was demonstrated in the radiation-induced polymerization of dry styrene ${ }^{21}$ and in catalyst-initiated cationic polymerizations. ${ }^{27,28}$

In Table I, kinetic results of wet styrene derivatives are given. The $R_{\mathrm{p}}$ value in styrene agreed well with the reference values ${ }^{19,31}$ of its radical polymerization when the dose-rate and temperature dependences were taken into account. Polymer yields are very low, less than $1 / 10$ of the radical rate of styrene in $p$-fluorostyrene $(p$-FST), $p$-chlorostyrene ( $p$-ClSt), 2,6-dimethylstyrene $\left(2,6-\mathrm{Me}_{2} \mathrm{St}\right)$, and 2,4,6-trimethylstyrene (2,4,6- $\left.\mathrm{Me}_{3} \mathrm{St}\right)$, while $R_{\mathrm{p}}$ 's in $2,3,4,5,6$-pentafluorostyrene $\left(\mathrm{F}_{5} \mathrm{St}\right)$ and $p$-bromostyrene $(p-\mathrm{BrSt})$ exceeded $R_{\mathrm{p}}$ of styrene. All the MW distribution curves of the polymers except poly $\left(\mathrm{F}_{5} \mathrm{St}\right)$, which
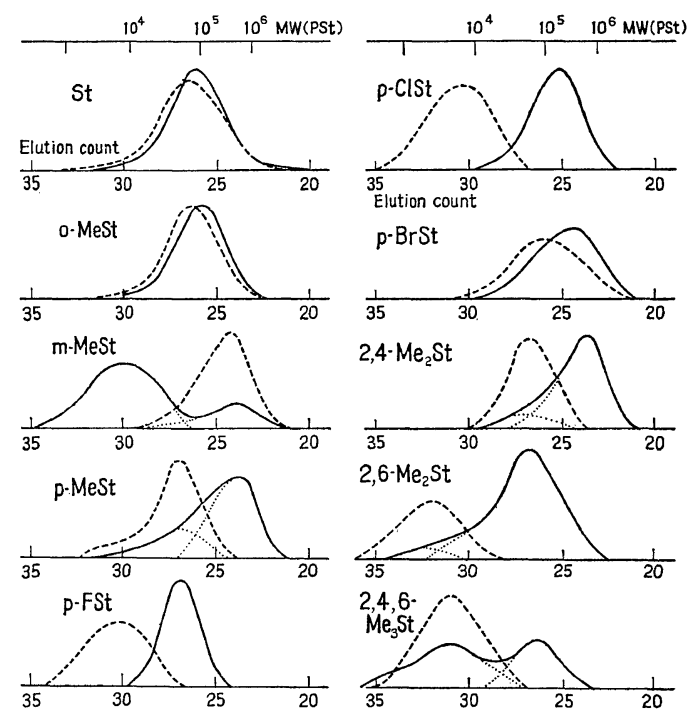

Figure 6. GPC curves of styrene derivative polymers: Broken line, wet system polymer; solid line, dry system polymer.

Table I. Polymerization of wet monomers ${ }^{a, b}$

\begin{tabular}{llccccccc}
\hline Code & Monomer & $\begin{array}{c}\text { Irradiation, } \\
\mathrm{hr}\end{array}$ & $\begin{array}{c}\text { Conversion, } \\
\%\end{array}$ & $\begin{array}{c}10^{6} \times R_{\mathrm{p}}, \\
M / \mathrm{sec}\end{array}$ & $G(-M)$ & $10^{-4} \times M_{n}$ & $10^{-4} \times M_{w}$ & $M_{w} / M_{n}$ \\
\hline W16 & Styrene & 48.3 & 8.8 & 4.4 & 760 & 3.4 & $>14.5$ & $>4.2$ \\
W5 & $o$-MeSt & 48.3 & 5.6 & 2.5 & 420 & 4.3 & 12.1 & 2.8 \\
W7 & $m$-MeSt & 48.3 & 6.9 & 3.0 & 520 & 12.9 & $\gg 46$ & $\gg 4$ \\
Y7 & $p$-MeSt & 93.0 & 3.2 & 0.73 & 130 & 2.5 & 5.3 & 2.2 \\
W11 & $p$-FSt & 48.3 & 0.80 & 0.39 & 60 & 0.78 & 1.02 & 1.3 \\
W12 & $p$-ClSt & 48.3 & 0.64 & 0.29 & 43 & 0.73 & 0.92 & 1.3 \\
W13 & $p$-BrSt & 48.3 & 65.7 & 28.9 & 3,520 & 6.3 & $\gg 25$ & $\gg 4$ \\
W14 & $\mathrm{F}_{5} \mathrm{St}$ & 48.3 & 15.2 & 6.5 & 760 & - & - & - \\
W3 & $2,4-\mathrm{Me}_{2} \mathrm{St}$ & 48.3 & 3.9 & 1.5 & 260 & 4.2 & 8.2 & 2.0 \\
$\mathrm{Y} 4$ & $2,6-\mathrm{Me}_{2} \mathrm{St}$ & 93.0 & 0.74 & 0.15 & 26 & 0.32 & 0.49 & 1.5 \\
$\mathrm{Y} 2$ & $2,4,6-\mathrm{Me} \mathrm{St}_{3} \mathrm{St}$ & 93.0 & 0.57 & 0.11 & 18 & 0.50 & 0.78 & 1.7 \\
\hline
\end{tabular}

a Dose rate, $2.07 \times 10^{4} \mathrm{rad} / \mathrm{hr}$ in water.

b Irradiation temp, $25-27.5^{\circ} \mathrm{C}$ (W series); $10-17^{\circ} \mathrm{C}$ ( $\mathrm{Y}$ series). 
Ionic Polymerization of $p$-Methoxystyrene by Radiation

Table II. Polymerization of dry monomers $\mathrm{s}^{\mathrm{a}, \mathrm{b}}$

\begin{tabular}{|c|c|c|c|c|c|c|c|c|}
\hline Code & Monomer & $\begin{array}{l}\text { Irradiation, } \\
\mathrm{hr}\end{array}$ & $\begin{array}{c}\text { Conversion, } \\
\%\end{array}$ & $\begin{array}{c}10^{6} \times R_{\mathrm{p}} \\
M / \mathrm{sec}\end{array}$ & $G(-M)$ & $10^{-4} \times M_{n}$ & $10^{-4} \times M_{w}$ & $M_{w} / M_{r}$ \\
\hline $\mathrm{X} 12$ & Styrene & 2.0 & 42.2 & 510 & 87,500 & 4.4 & $\gg 17$ & $\gg 4$ \\
\hline $\mathrm{X} 5$ & $o$-MeSt & 39.5 & 9.2 & 5.0 & 850 & 5.7 & 15.2 & 2.7 \\
\hline \multirow[t]{3}{*}{$\mathrm{X} 4$} & $m$-MeSt & 15.4 & 13.7 & 18.8 & 3,230 & 0.90 & $>13$ & $>15$ \\
\hline & & & & & & 0.76 & 1.13 & 1.5 \\
\hline & & & & & & 15.6 & $>56$ & $>4$ \\
\hline \multirow[t]{3}{*}{$\mathrm{X} 6$} & $p$-MeSt & 39.5 & 1.6 & 0.87 & 150 & 7.4 & $\gg 51$ & $\gg 7$ \\
\hline & & & & & & 3.0 & 5.3 & 1.8 \\
\hline & & & & & & 23 & $\gg 66$ & $\gg 3$ \\
\hline $\mathrm{X} 7$ & $p$-FSt & 39.5 & 2.9 & 1.7 & 260 & 4.3 & 6.6 & 1.5 \\
\hline $\mathrm{X} 8$ & $p$-ClSt & 15.4 & 12.7 & 17.8 & 2,670 & 10.1 & $>27$ & $>2.7$ \\
\hline $\mathrm{X} 9$ & $p$-BrSt & 6.0 & 17.4 & 61.6 & 7,500 & 10.8 & $\gg 45$ & $\gg 4$ \\
\hline $\mathrm{X} 10$ & $\mathrm{~F}_{5} \mathrm{St}$ & 15.4 & 34.6 & 46.6 & 5,450 & - & - & - \\
\hline \multirow[t]{3}{*}{$\mathrm{X} 2$} & $2,4-\mathrm{Me}_{2} \mathrm{St}$ & 15.4 & 6.8 & 8.4 & 1,420 & 15.4 & $\gg 65$ & $\gg 4$ \\
\hline & & & & & & 4.0 & 7.7 & 1.9 \\
\hline & & & & & & 26 & $\gg 74$ & $\gg 3$ \\
\hline \multirow[t]{3}{*}{ Y3 } & 2,6-Me $\mathrm{Me}_{2} \mathrm{St}$ & 93.0 & 4.4 & 0.90 & 150 & 2.0 & 10.5 & 5.3 \\
\hline & & & & & & 0.34 & 0.45 & 1.3 \\
\hline & & & & & & 3.1 & 14.3 & 4.6 \\
\hline \multirow[t]{3}{*}{$\mathrm{X} 1$} & $2,4,6-\mathrm{Me}_{3} \mathrm{St}$ & 39.5 & 0.42 & 0.18 & 31 & 0.88 & 4.5 & 5.2 \\
\hline & & & & & & 0.55 & 0.76 & 1.4 \\
\hline & & & & & & 5.2 & 9.8 & 1.9 \\
\hline
\end{tabular}

a Dose rate, $2.07 \times 10^{4} \mathrm{rad} / \mathrm{hr}$ in water.

b Irradiation temp, $12-15^{\circ} \mathrm{C}\left(\mathrm{X}\right.$ series); $10-17^{\circ} \mathrm{C}$ (Y3).

is insoluble to GPC solvent, are single-peaked in appearance, as shown with the broken line curves in Figure 6. From the low $R_{\mathrm{p}}$ values and the unimodal GPC curves, we can see that the radical mechanism is predominant in most of the monomers, except $p$ - $\mathrm{BrSt}$ and $\mathrm{F}_{5} \mathrm{St}$. In $p-\mathrm{BrSt}$, the value of $R_{\mathrm{p}}$ which is 6.5 times greater than styrene may be accounted for by the 2.7 times greater $k_{\mathrm{p}} / k_{\mathrm{t}}{ }^{1 / 2}$ value $^{32}$ relative to styrene and probably by the greater radical yield which is common in chlorinated compounds. However, we have no theory for the high $R_{\mathrm{p}}$ in $\mathrm{F}_{5} \mathrm{St}$.

Further drying by silica gel gave an improvement of $R_{\mathrm{p}}$ by $2-100$ times, allowing the appearance of a second peak on the GPC curves of several polymers, as shown with the solid line curves in Figure 6. The kinetic results are given in Table II. The exceedingly high $R_{\mathrm{p}}$ attained in styrene indicates that our drying technique itself is not different from that used in our previous study. ${ }^{3}$ However the $R_{\mathrm{p}}$ 's are still lower than the radical rate of styrene for some reason in $p$-methylstyrene ( $p$-MeSt), $p$-FSt, 2,6-Me $\mathrm{Me}_{2} \mathrm{St}$, and $2,4,6-\mathrm{Me}_{3} \mathrm{St}$. A difference in polymerization temperature between wet and dry systems gives a small complication in comparing $R_{\mathrm{p}}$ and $\mathrm{MW}$ in the two systems. In several monomers in which bimodal distributions were obtained, attempts were made to resolve the total curve into two components from the comparison of the MW distributions of wet and dry system polymers. The values obtained for each fraction are also listed in Table II.

Here we have four different cases, as follows: I. A bimodal distribution was obtained in the dry system, one peaks being in the identical position with that of the wet system polymer. This is the case in $m$-methylstyrene ( $m$-MeSt) and 2,4,6-Me $\mathrm{Me}_{3} \mathrm{St}$. II. A new, higher MW peak was found in the dry system polymer, with a long tail in the lower MW region which covered the whole MW range of the wet system polymer. This is the case in $p$-MeSt, 2,4-dimethylstyrene (2,4-Me $\left.\mathrm{Me}_{2} \mathrm{St}\right)$, and $2,6-\mathrm{Me}_{2} \mathrm{St}$. III. We failed to obtain a bimodal distribution; however, a high $R_{\mathrm{p}}$ value, greatly exceeding the radical rate of styrene, was obtained in the dry system in $p$-ClSt, $p$-BrSt, $\mathrm{F}_{5} \mathrm{St}$, and styrene. IV. Neither a bimodal 


\section{K. Hayashi and D. C. Pepper}

distribution nor a high $R_{\mathrm{p}}$ value was obtained in $o$-methylstyrene $(o-\mathrm{MeSt})$ or in $p$-FSt, probably.

In cases I and II, it is very likely that two types of polymerization, radical and ionic, are coexisting in the dry system. Low $R_{\mathrm{p}}$ 's in 2,6$\mathrm{Me}_{2} \mathrm{St}$ and 2,4,6-Me $\mathrm{St}$ can be explained by the steric hindrance by two ortho methyl groups. ${ }^{33}$ However, this does not account for the low $R_{\mathrm{p}}$ in $p$-MeSt. $m$-MeSt was the only instance in this study that the radical mechanism gave a greater MW than the cationic mechanism did.

In monomers of case III, the $R_{\mathrm{p}}$ values in the dry system are considerably greater than that of styrene in radical mechanism. In $p$-ClSt, a singlepeaked distribution was obtained in the dry system at a different $\mathrm{MW}$ region from that of the wet system polymer. This is well understood in terms of the high $R_{\mathrm{p}}$ ratio between the dry and wet systems, ca. 60, if the $R_{\mathrm{p}}$ increase in the dry system is exclusively attributable to an ionic mechanism. In $p$-BrSt, a broad, singlepeaked distribution was obtained in the wet system polymer, while the dry system polymer showed a broad, asymmetric curve of higher MW covering most of the wet system polymer range. This implies that the dry system polymer is a mixture of two polymers of relatively close MW's, one component being similar to the wet system polymer curve. In $\mathrm{F}_{5} \mathrm{St}$, a value of $R_{\mathrm{p}}$ ten times greater than the radical rate of styrene was obtained in the dry system. A kinetic study in radical polymerization ${ }^{34}$ indicated that the $k_{\mathrm{p}} / k_{\mathrm{t}}{ }^{1 / 2}$ value in $\mathrm{F}_{5} \mathrm{St}$ is nearly the same as that of styrene at $60^{\circ} \mathrm{C}$. As $R_{\mathrm{p}}$ is proportional to the square root of the radical yield, $c a .100$ times greater radical yield relative to that in styrene, which is very unlikely, is required to explain the ten times greater $R_{\mathrm{p}}$ in $\mathrm{F}_{5} \mathrm{St}$ with radical mechanism. For these reasons, we consider that ionic polymerizations are also likely in these three halostyrenes.

In the case of styrene, it is clear from the $R_{\mathrm{p}}$ values that the wet and dry system polymers are to be attributed exclusively to radical and cationic mechanisms, respectively, though their GPC curves are very similar. Taking account of the temperature and dose-rate dependence of the MW of radical polymers, ${ }^{19,31}$ it is desirable to use a much higher dose-rate and lower temperature to demonstrate a bimodal distribution in styrene. ${ }^{7,21}$
In $o$-MeSt, $R_{\mathrm{p}}$ 's are as low as the radical rate of styrene and their GPC curves are similar and unimodal, i.e., there is no indication of an ionic mechanism at all. In $p$-FST, $R_{\mathrm{p}}$ 's in the two systems are 9 and $39 \%$ of the radical rate of styrene, though their GPC curves appeared at different regions. From their $R_{\mathrm{p}}$ values, it is strange that a bimodal distribution was not obtained in the dry system if the $R_{\mathrm{p}}$ increase by drying is due to an ionic mechanism, as was supposed in most of the monomers above.

It seems likely that most of these styrene derivatives can polymerize cationically ${ }^{35}$ and also anionically $^{25}$ by a suitable choice of catalyst. However, very little is known about the ionic polymerization of these compound by radiation. $\mathrm{Chen}^{36}$ inferred a cationic nature in the $2,4-\mathrm{Me}_{2} \mathrm{St}$ polymerization in methylene chloride at low temperature. In $p$-ClSt, Yamaoka ${ }^{37}$ found a cationic mechanism at $-78^{\circ} \mathrm{C}$ and a radical mechanism at $9^{\circ} \mathrm{C}$ in methylene chloride, suggesting a similar trend in $p$-BrSt. On the other hand, no anionic polymerization by radiation has been found even in styrene. Really, the anionic mechanism is somehow less likely to take place by radiation initiation than the cationic mechanism. So far, only two monomers, nitroethylene ${ }^{38}$ and acrylonitrile, ${ }^{39}$ have been known to polymerize anionically in bulk. For this reason, we consider that the cationic mechanism is much more likely in most of styrene derivatives studied.

Acknowledgment. The authors express their gratitude to Dr. J. E. O'Connor, St. Lukes Hospital, Dublin, for his continued kindness in allowing use of the irradiation facilities. One of us (K.H.) wishes to thank the National Science Council, Ireland, for his postdoctoral fellowship.

\section{REFERENCES}

1. E. Hubmann, R. B. Taylor, and F. Williams, Trans. Faraday Soc., 62, 88 (1966).

2. F. Williams, Ka. Hayashi, K. Ueno, Ko. Hayashi, and S. Okamura, ibid., 63, 1501 (1967).

3. Ka. Hayashi, Ko. Hayashi, and S. Okamura, Polymer J., 4, 426 (1973).

4. K. Ueno, H. Yamaoka, Ko. Hayashi, and S. Okamura, Int. J. Appl. Rad. \& Isotopes, 17, 513 (1966); K. Ueno, F. Williams, Ko. Hayashi, 
Ionic Polymerization of $p$-Methoxystyrene by Radiation

and S. Okamura, Trans. Faraday Soc., 63, 1478 (1967).

5. R C. Potter, C. L. Johnson, D. J. Metz, and R. H. Bretton, J. Polym. Sci., Part A-1, 4, 419 (1966); R. C. Potter, R. H. Bretton, and D. J. Metz., ibid., Part A-1, 4, 2295 (1966); R. C. Potter and D. J. Metz, ibid., Part $A-1$, 9, 441 (1971).

6. F. W. Burns, R. M. O'Connor, and D. C. Pepper, ibid., Part B, 5, 1059 (1967).

7. S. Machi, J. Silverman, and D. J. Metz, J. Phys. Chem., 76, 930 (1972).

8. D. J. Metz, Adv. Chem., 66, 170 (1967).

9. Ka. Hayashi, Ko. Hayashi, and S. Okamura, J. Polym. Sci., Part A-1, 9, 2305 (1971).

10. J. Kohler and V. Stannett, Polymer Reprints, 12, 98 (1971).

11. R. B. Taylor and F. Williams, J. Amer. Chem. Soc., 91, 3728 (1969).

12. J. P. Kennedy, A. Shinkawa, and F. Williams, J. Polym. Sci., Part A-1, 9, 1551 (1971).

13. J. P. Kennedy in "Copolymerization," G. E. Ham, Ed., Interscience Publishers Inc., New York, N. Y., 1964, p 283.

14. Ka. Hayashi, Ko. Hayashi, and S. Okamura, Polymer J., 4, 495 (1973).

15. J. Geerts, M. Van Beylen, and G. Smets, $J$. Polym. Sci., Part A-1, 7, 2859 (1969).

16. W. J. Burlant and D. H. Green, ibid., 31, 227 (1958).

17. C. S. H. Chen, ibid., Part A, 1, 1293 (1963).

18. J. F. Westlake and R. Y. Huang, ibid., Part A-1, 10, 1429 (1972).

19. A. Chapiro, "Radiation Chemistry of Polymeric Systems," High Polymers Series, No. 15, Interscience Publishers Inc., New York, N. Y., 1962, p 164.

20. K. H. Bagdasaryan, "Theory of Radical Polymerization," M. Imoto and S. Futami, Translators, Asakura Shoten, Tokyo, 1964, p 107.

21. J. F. Westlake and R. Y. Huang, J. Polym. Sci., Part $A-1,10,1443$ (1971).
22. C. Walling, E. R. Briggs, K. B. Wolfstirn, and F. R. Mayo, J. Amer. Chem. Soc., 70, 1537 (1948).

23. Y. Imanishi, S. Matsushita, T. Higashimura, and S. Okamura, Makromol. Chem., 70, 68 (1964).

24. A. V. Tobolsky and B. J. Boudreau, J. Polym. Sci., 51, S53 (1961).

25. M. Shima, D. N. Bhattacharyya, J. Smid, and M. Szwarc, J. Amer. Chem. Soc., 85, 1306 (1963).

26. T. Masuda and T. Higashimura, Polymer J., 2, 29 (1971).

27. D. C. Pepper, Makromol Chem., 175, 1077 (1974).

28. T. Higashimura and T. Masuda, Polymer J., 5, 278 (1973); T. Higashimura and O. Kishiro, J. Polym. Sci., Part A-1, 12, 967 (1974).

29. C. E. H. Bawn, C. Fitzsimmons, A. Ledwith, J. Penfold, D.C. Sherrington, and J. A. Weightman, Polymer, 12, 119, (1971).

30. P. M. Bowyer, A. Ledwith, and D. C. Sherrington, ibid., 12, 509 (1971).

31. R. Y. Huang, J. F. Westlake, and S. C. Sharma, J. Polym. Sci., Part A-1, 7, 1729 (1969).

32. M. Kinoshita, M. Nishigaki, and M. Imoto, Kogyo Kagaku Zasshi (J. Chem. Soc. Japan, Ind. Chem. Sect.) 68, 104 (1965).

33. A. de Pauw and G. Smets, Bull. Soc. Chim. Belges, 59, 629 (1950).

34. W. A. Pryor and T. L. Huang, Macromolecules, 2, 70, (1969).

35. C. G. Overberger, L. H. Arond, D. Tanner, J. J. Taylor, and T. Alfrey, J. Amer. Chem. Soc., 74, 4848 (1952).

36. C. S. H. Chen and R. F. Stamm, J. Polym. Sci., 58, 369 (1962).

37. H. Yamaoka, K. Nishiyama, and S. Okamura, Kobunshi Kagaku (Chem. High Polymers), 24, 649 (1967).

38. H. Yamaoka, F. Williams, and Ko. Hayashi, Trans. Faraday Soc., 63, 376 (1967).

39. S. Iiyama, S. Abe, and K. Namba, J. Polym. Sci., Part B, 11, 81 (1973). 